\title{
Design of beryllium window for Brookhaven Linac Isotope Producer
}

\section{S. Nayak, M. Mapes, L. Smart, D. Weiss}

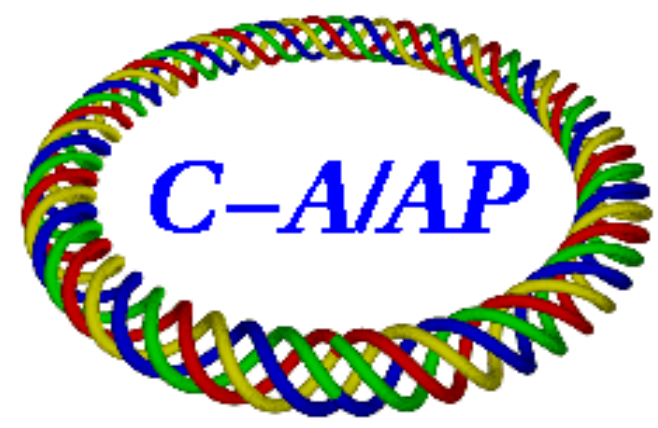

\section{Collider-Accelerator Department Brookhaven National Laboratory Upton, NY 11973}

\author{
U.S. Department of Energy \\ Office of Science, Office of Nuclear Physics
}

Notice: This document has been authorized by employees of Brookhaven Science Associates, LLC under Contract No. DE-SC0012704 with the U.S. Department of Energy. The United States Government retains a nonexclusive, paid-up, irrevocable, world-wide license to publish or reproduce the published form of this document, or allow others to do so, for United States Government purposes. 


\title{
Design of Beryllium window for Brookhaven Linac Isotope Producer
}

\author{
S. Nayak, M. Mapes, D. Raparia \\ Brookhaven National Lab, Upton, NY, USA
}

\begin{abstract}
In the Brookhaven Linac Isotope Producer (BLIP) beam line, there were two Beryllium (Be) windows with an air gap to separate the high vacuum upstream side from low vacuum downstream side. There had been frequent window failures in the past which affected the machine productivity and increased the radiation dose received by worker due to unplanned maintenance. To improve the window life, design of Be window is reexamined. Detailed structural and thermal simulations are carried out on Be window for different design parameters and loading conditions to come up with better design to improve the window life. The new design removed the air gap and connect the both beam lines with a Be window in-between. The new design has multiple advantages such as 1) reduces the beam energy loss (because of one window with no air gap), 2) reduces air activation due to nuclear radiation and 3) increased the machine reliability as there is no direct pressure load during operation. For quick replacement of this window, an aluminum bellow coupled with load binder was designed. There hasn't been a single window failure since the new design was implemented in 2012.
\end{abstract}

\section{Introduction}

The BLIP consists of a beam line and target area for isotope production that uses protons up to $200 \mathrm{MeV}$ energy and $110 \mu \mathrm{A}$ intensity from the BNL Linac. At the end of the beam line, there is an AlBeMet window which acts as a structural barrier between atmospheric pressure and vacuum, and at the same time it allows the beam to pass through it without much loss. This window is more prone to failure due to corrosion and overheating. Also the last part of beamline is at low vacuum due to presence of graphite collimators. For easy replacement \& maintenance of AlBeMet window without venting the whole beamline and to separate high vacuum upstream side from low vacuum downstream side, the very end of the beam line is separated from the rest of the beam line by Berrylium (Be) windows. The old Be window system used two windows with an air gap in between. The old system had multiple drawbacks, frequent failures due to atmospheric corrosion, localized radioactive contamination from activation of air molecules and more beam loss due to air gap. Frequent failure of $\mathrm{Be}$ window increases machine downtime and decreases productivity. Any unplanned maintenance to replace the Be window ended up with workers getting high radiation dose and increasing the chances of health hazards. To address the above issues, better and robust window system is designed and presented in this report. 


\section{Old Window}
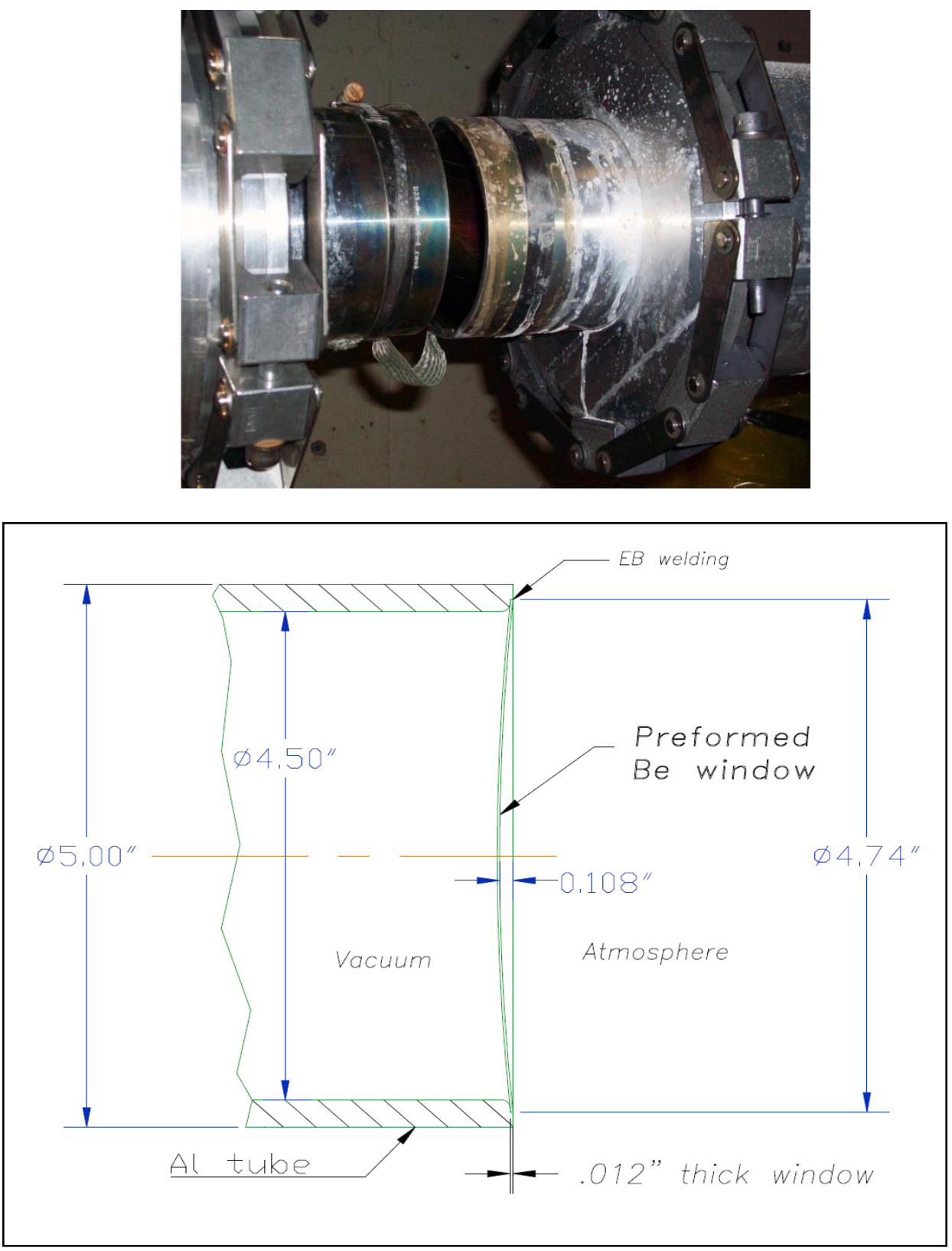

Fig 2-1: Be windows in BLIP and dimension details

Fig 2-1 shows the two Be windows, facing each with an air gap, separates the low vacuum downstream side from high vacuum upstream side. The beam loss is higher as the beam has to pass through two windows and air gap. The radiation level increases due to activation air molecules. Since Be is highly reactive to water, life of window would be shortened as it is exposed to water vapors present in air. The Be window is welded to $\mathrm{Al}$ tube and detailed dimensions are shown in this figure. 
This window is fabricated and supplied by Brush Wellman. Fabrication steps are as follows.

1. Water jet cut the beryllium disc from a 0.030 " thick sheet.

2. Chemical etch the $0.030 "$ thick input material to a $0.013 "$ thick gauge.

3. Hot form the beryllium to 48 " radius (or any specified radius) of curvature at a temperature between $1300-1400^{\circ} \mathrm{F}$.

4. Remove oxides caused by the forming process

5. Chemical etch the beryllium to final thickness requirement of $0.012 " \pm 0.0012 "$

6. Machine formed beryllium to final diameter $\varnothing 4.924 "+0.000 /-0.002 "$

7. Inspect

8. Electron beam weld to aluminum tube

9. Leak test

10. Alodine

11. Final quality control check.

Since the window is formed at $1300-1400{ }^{0} \mathrm{~F}$, it is assumed that the window is free from any prestress.

\section{Finite Element Analysis (FEA) of window}

Thermal analyses are first carried out to find the temperature distribution in the window. All three modes of heat transfers are considered. Then temperature load along with pressure load are used in the stress analysis. Fig 2-2 shows the $1 / 4^{\text {th }}$ symmetric finite element model. Modelling of heat load and heat transfer modes are shown in Fig 2-3. Al tube and flange act as heat sink and release heat through convection. For stress analysis, a small section of tube attached to window is considered (Fig 2-8). The window and tube are modeled with shell and solid elements respectively. The outer edge of the window is attached to the tube. At the contact, fillet radius in tube and suitable contact elements (Fig 2-9) are defined so that when window deforms under pressure touch the tube surface. Without these considerations, stress and deformation of window will be unrealistically high.

\section{Thermal Simulation}

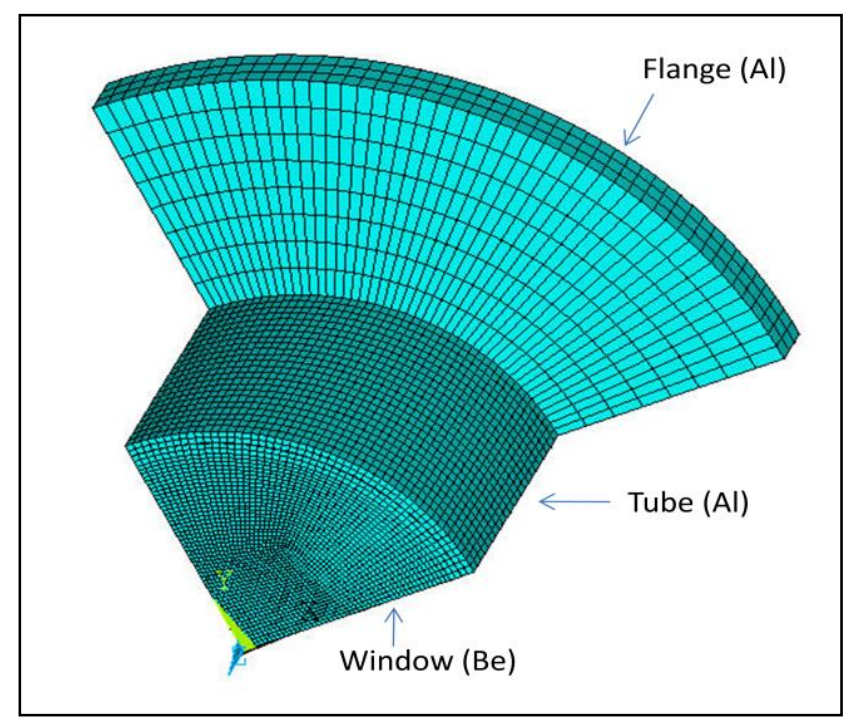

Fig 2-2: $1 / 4^{\text {th }}$ symmetric finite element model for thermal analysis 


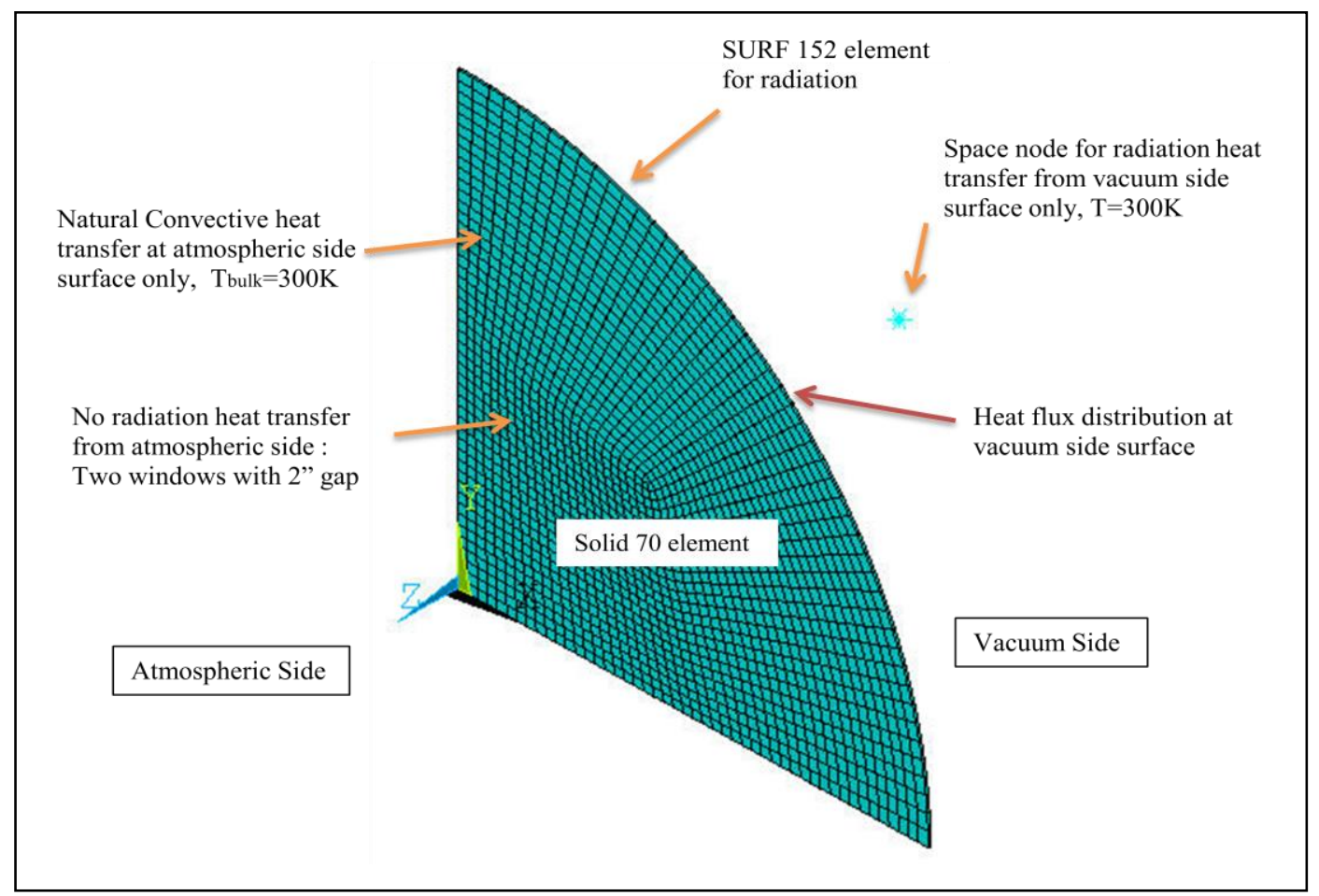

Fig 2-3: Heat load and transfer details of the window

Heat flux load

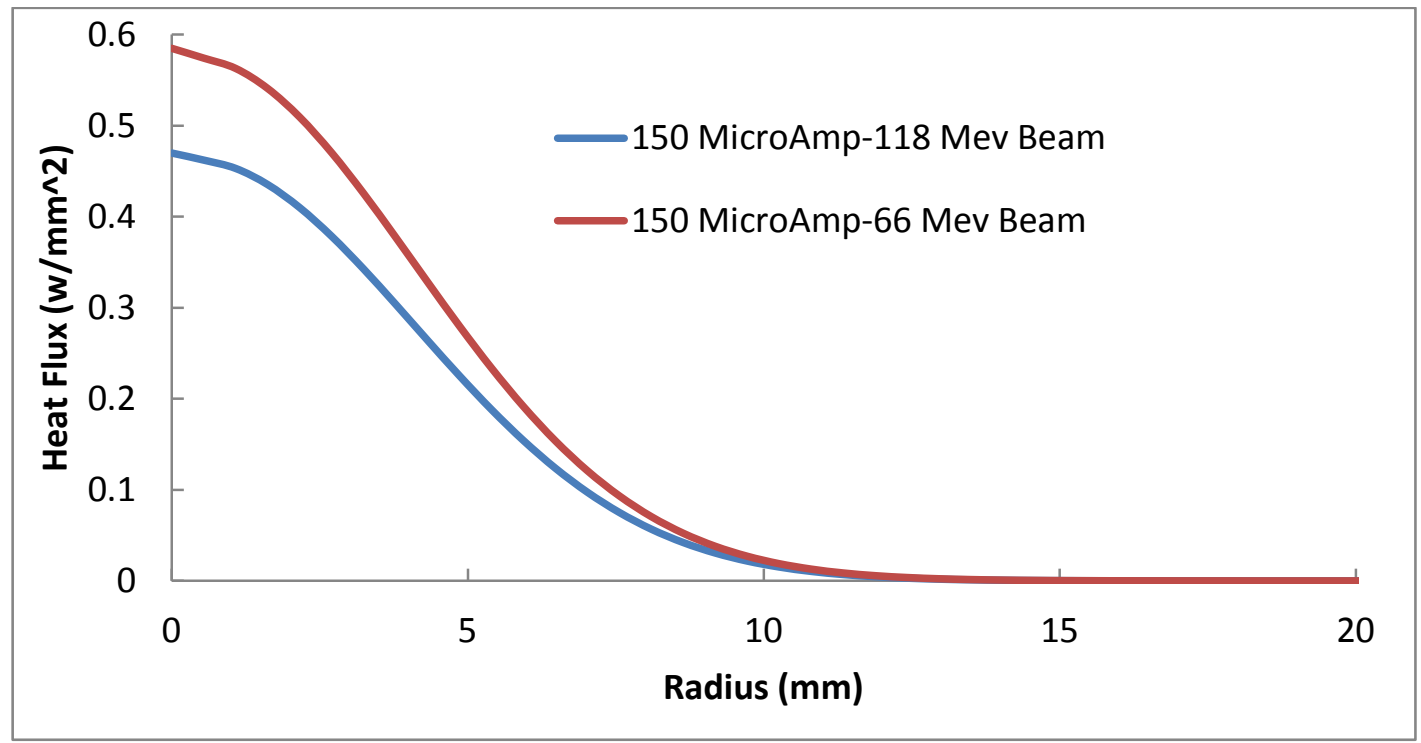

Fig 2-4: Heat flux load on the window (Gaussian distribution)

\section{Conduction heat transfer}

Conduction mode of heat transfer is taken care by defining the beryllium's thermal conductivity which is $216 \mathrm{~W} / \mathrm{m}-\mathrm{k}$. 
Convective heat transfer

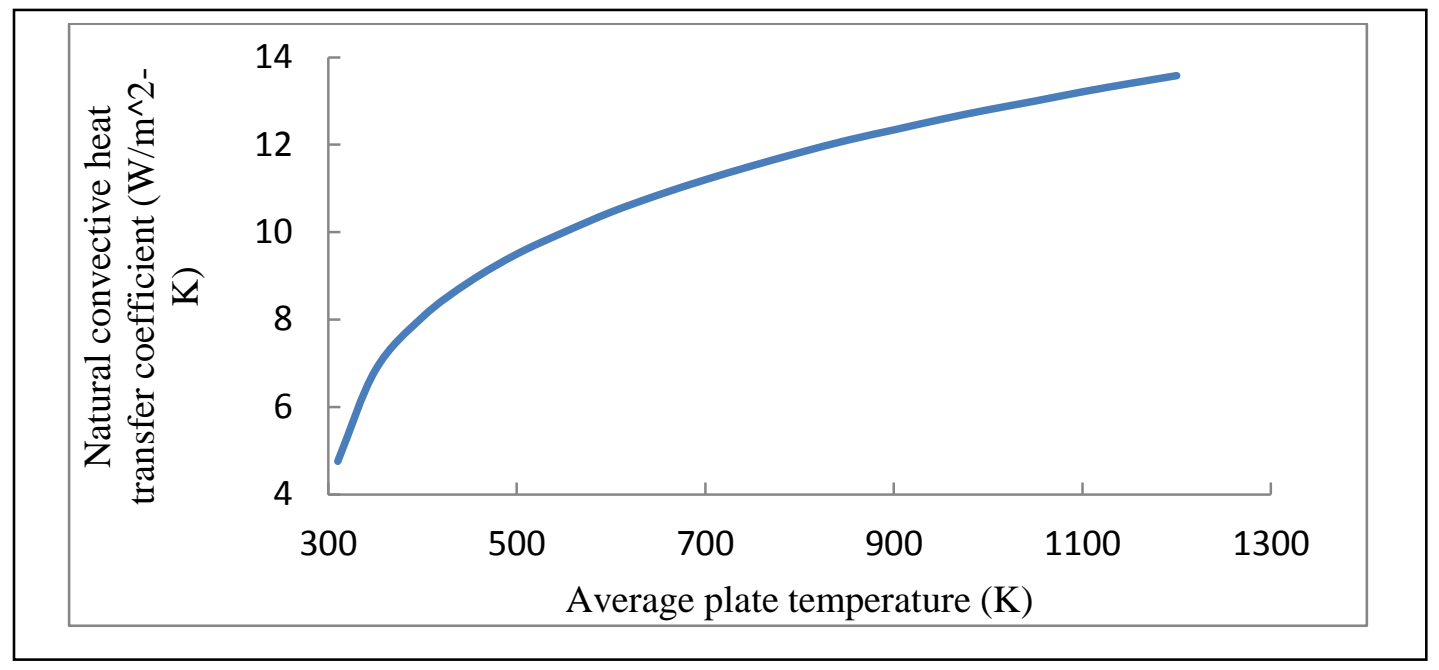

Fig 2-5: Natural convective heat transfer coefficient $\left(\mathrm{W} / \mathrm{m}^{\wedge} 2-\mathrm{k}\right)$

Natural convective heat transfer is considered for a vertical circular plate [1] and applied to outer face of the window, tube and the flange. All the parameters controlling the convection coefficient are considered including air properties variation with temperature.

\section{Radiation heat transfer}

Since there are two such windows separated by $\sim 2$, , radiation heat transfer from vacuum side surface is only considered. Emissivity of the Be is 0.61 and view factor is taken as 1 .

\section{Results}

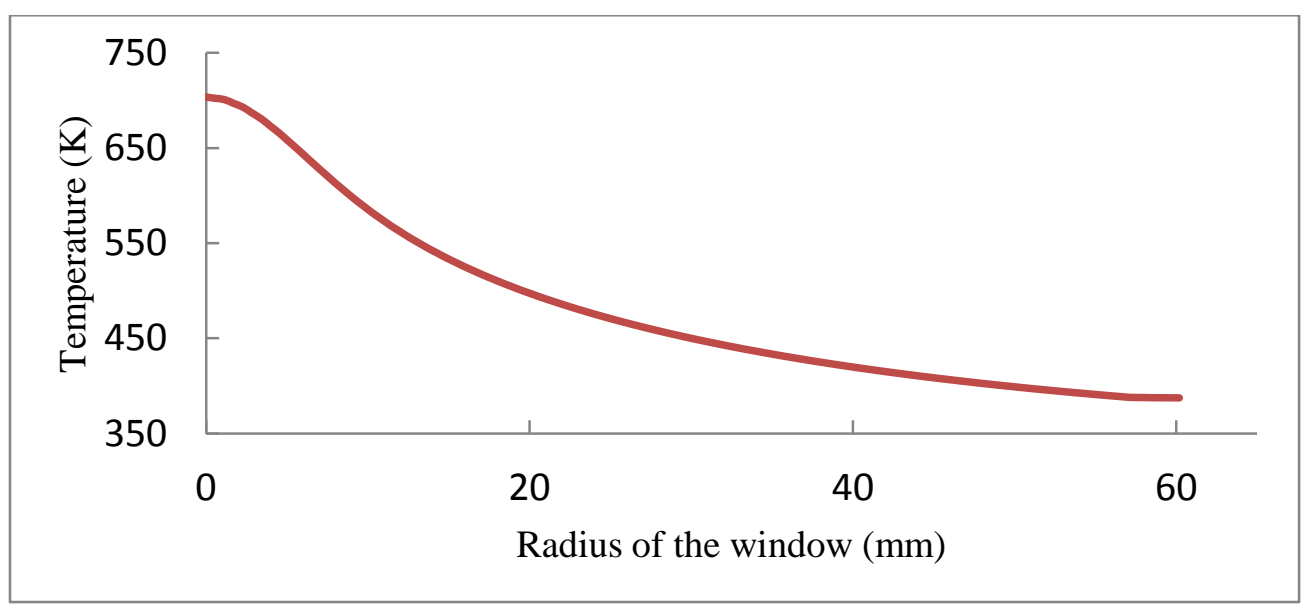

Fig 2-6: Temperature distribution in the window (66Mev).

Trend line is fitted in the above plot and an analytical expression is generated in terms of radius is generated. This expression is used to apply thermal load in structural analysis. 
$\mathrm{T}=-1.6 \mathrm{e}-7 * \mathrm{r}^{6}+3.14 \mathrm{e}-5 * \mathrm{r}^{5}-2.34 \mathrm{e}-3 * \mathrm{r}^{4}+8 \mathrm{e}-2 * \mathrm{r}^{\wedge} 3-1.04 * \mathrm{r}^{2}-7.7 * \mathrm{r}+711.13, \mathrm{r}$ is the radial location in window

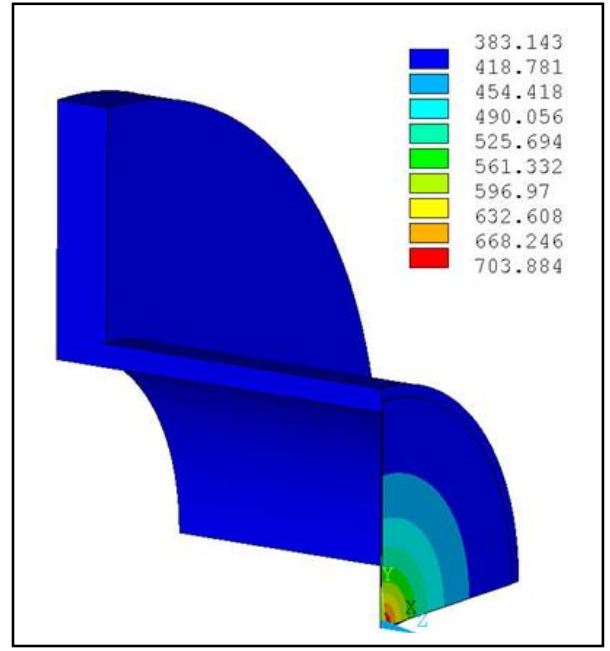

(a)

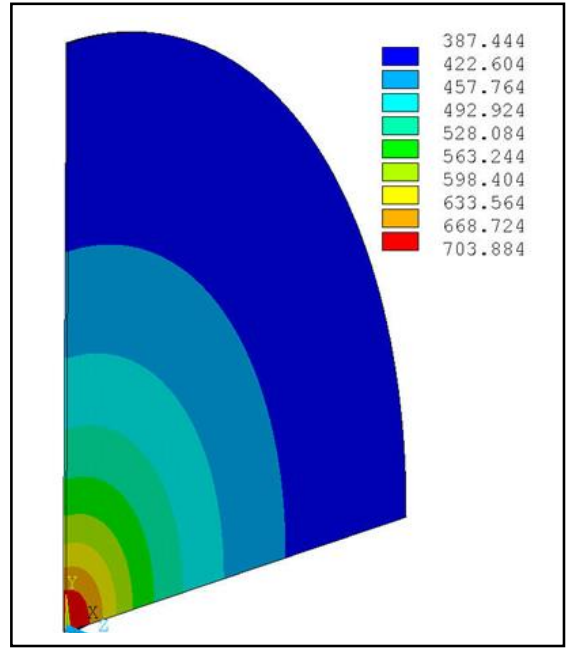

(b)

Fig 2-7: Contour plot of temperature (k) (a) full $1 / 4^{\text {th }}$ symmetric model and (b) only window

\section{Stress analysis of window}

\section{Assumptions}

Since the window is hot formed at $1300-1400$ F, no pre-stress effect is considered.

Finite element Modeling

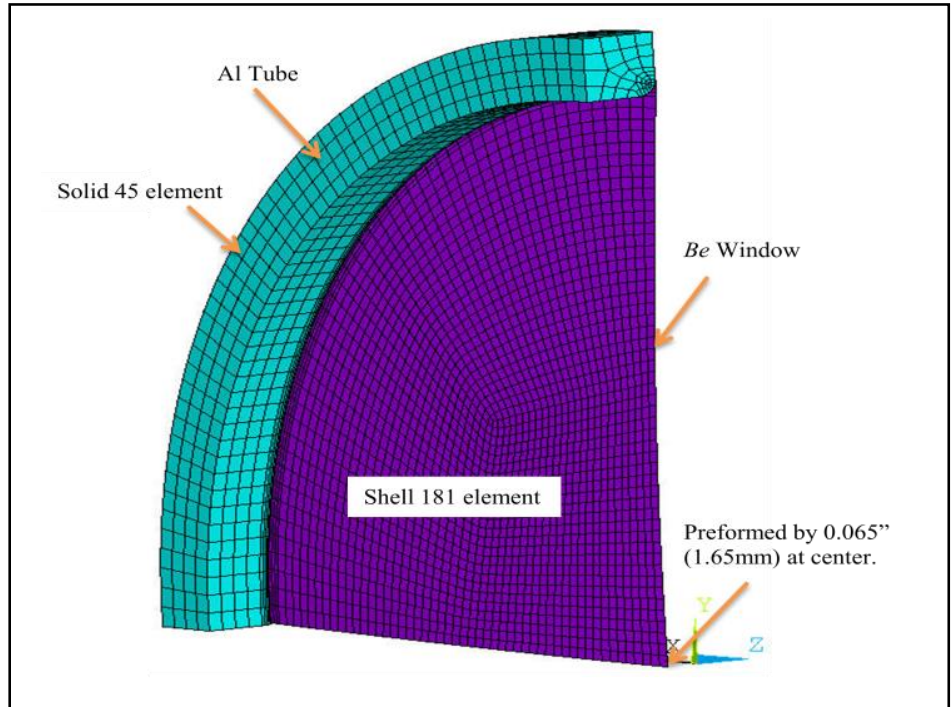

Fig 2-8: $1 / 4^{\text {th }}$ symmetric model (48" radius of curvature-window) 


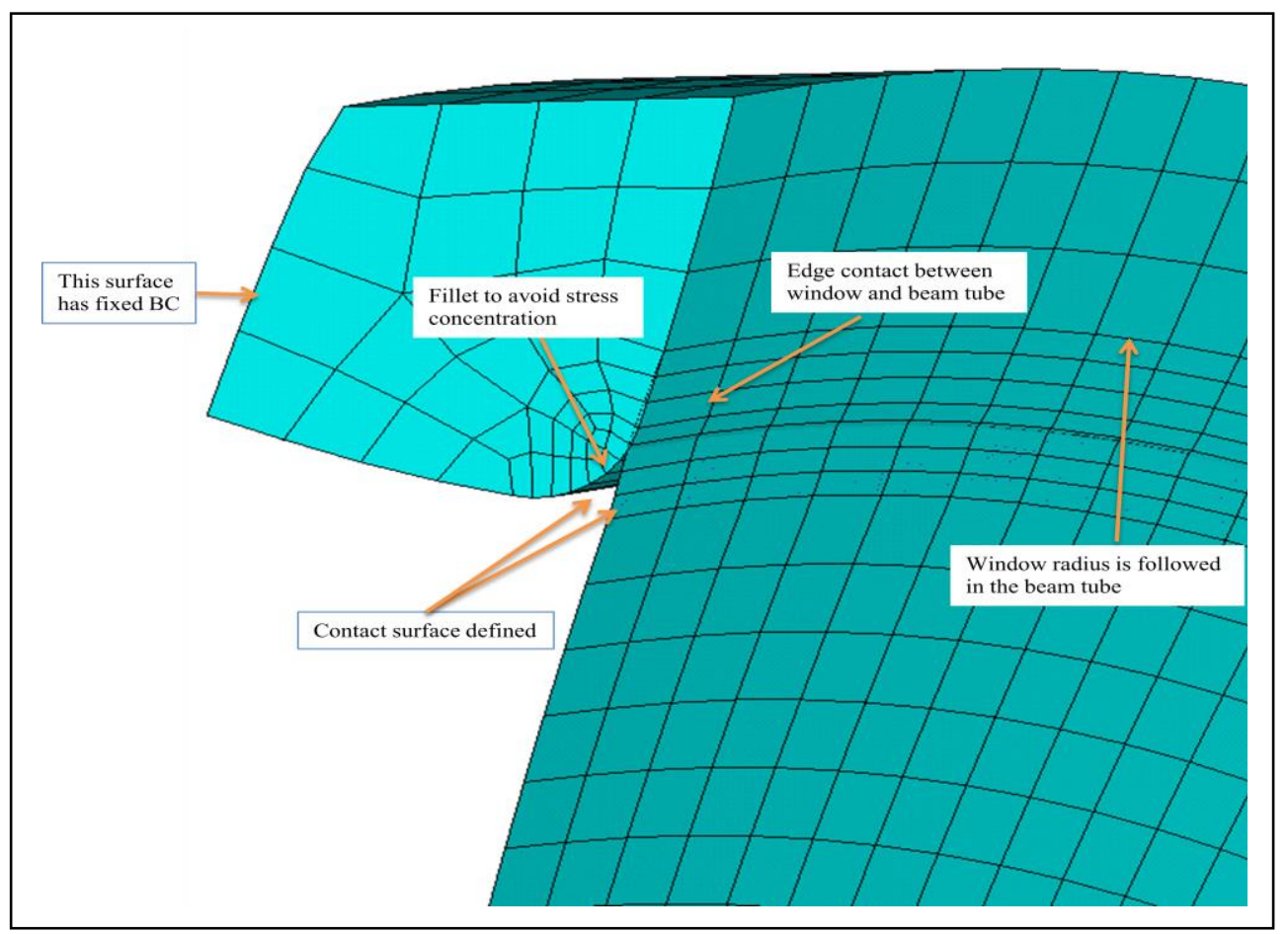

Fig 2-9: Contact between window and tube

\section{Material Properties}
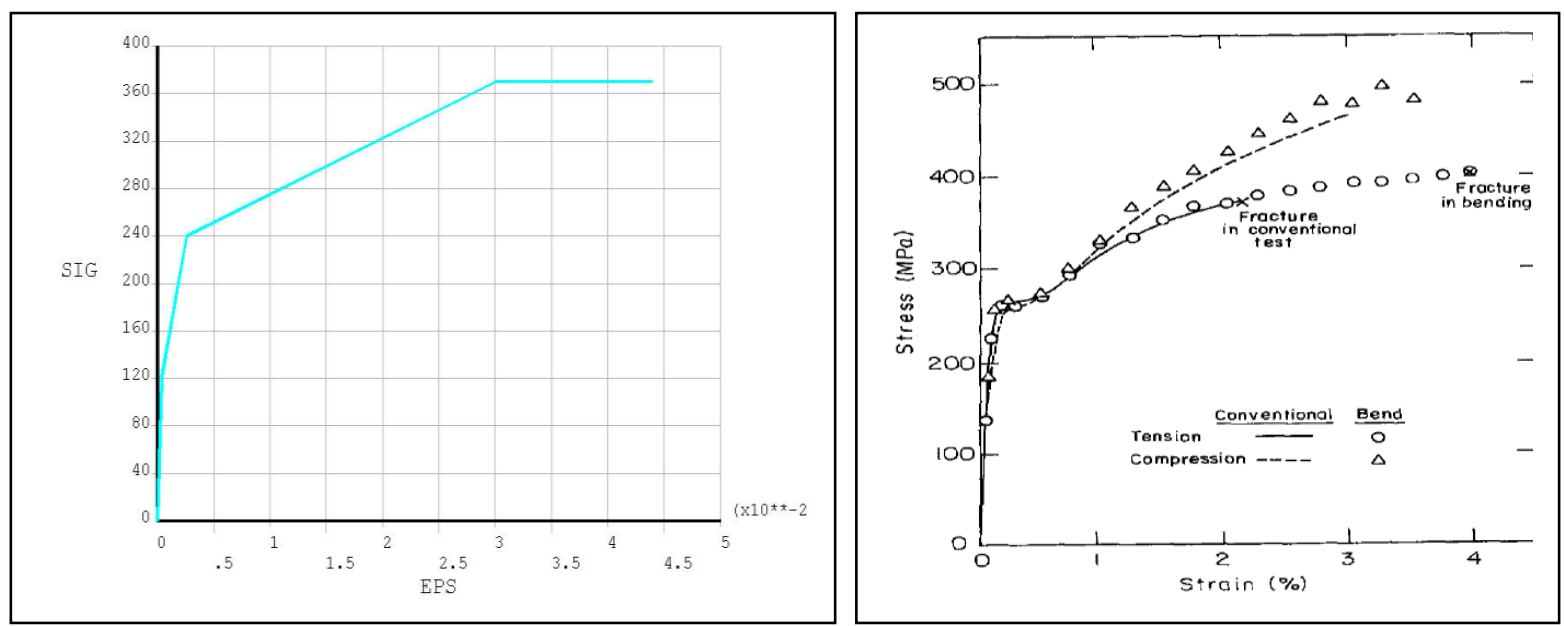

Fig 2-10: Material properties of the pure Be/PF-60 (a) multi-linear isotropic hardening material model used in ANSYS, strain is in x-axis and stress (MPa) in y-axis. (b) stress-strain plot obtained from literature [2] 
Table 2-1: Material properties of Beryllium PF-60/Pure Be and Al

\begin{tabular}{|l|l|l|}
\hline Property & Be (PF-60) & Al \\
\hline Elastic modulus, GPa (MPsi) & $303(43.94)$ & -- \\
\hline Poisson's ratio $\left(^{*}\right)$ & $0.07-0.18$ & -- \\
\hline Yield stress, MPa (KPsi) & $240(34.8)$ & -- \\
\hline Ultimate stress, MPa (KPsi) & 370 & -- \\
\hline Thermal Conductivity (w/m-k) & 216 & 167 \\
\hline $\begin{array}{l}\text { Coefficients of thermal } \\
\text { expansion }(\mu \mathrm{m} / \mathrm{m}-\mathrm{C})\end{array}$ & 11.5 & 23.6 \\
\hline Emissivity & 0.61 & -- \\
\hline Melting temperature, C (F) & $1273(2323.4)$ & $600(1112)$ \\
\hline
\end{tabular}

*Average Poisson's ratio is taken for analysis i.e 0.125. Effect of Poisson's ratio on the result is insignificant.

Results

Fig 2-11 shows the contour plot for 48" radius window with thermal (66 Mev beam energy-150 $\mu$ amp beam current) and atmospheric load. The Von Misses stress exceeds the yield stress (240 MPa) and maximum stress occurs at the outer periphery of the window. This is obvious as the outer periphery doesn't have much scope to undergo thermal expansion and to release the stress.

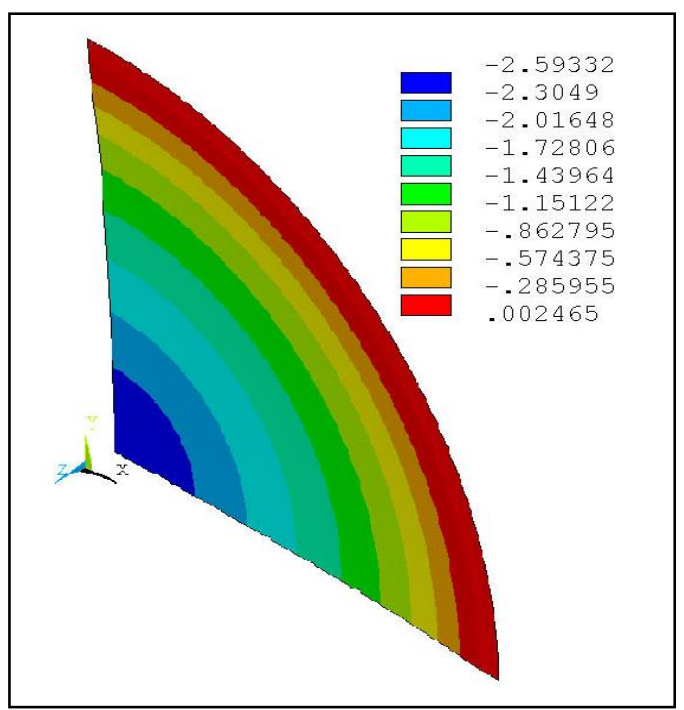

(a)

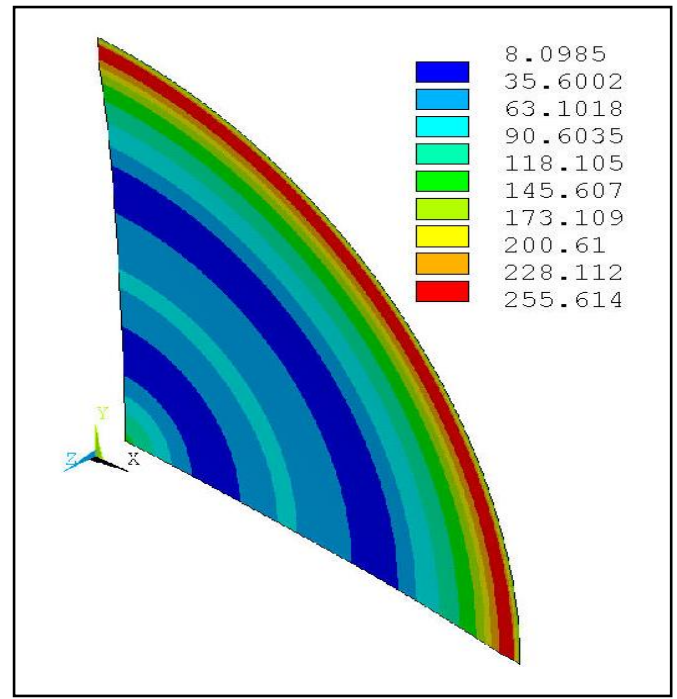

(b)

Fig 2-11: a) Axial deflection ( $\mathrm{mm}$ ) and (b) Von Misses stress (MPa) 
Table 2-2: Maximum stress and factor of safety for 0.012" thick Be (PF-60) window (Note: The maximum stress in most cases are $1^{\text {st }}$ principal stress)

\begin{tabular}{|c|c|c|c|c|c|c|c|c|c|c|c|c|}
\hline \multirow{3}{*}{$\begin{array}{l}\text { Radius of } \\
\text { curvature }\end{array}$} & \multicolumn{3}{|c|}{ Vacuum Load } & \multicolumn{9}{|c|}{ Vacuum + Thermal Load } \\
\hline & \multirow{2}{*}{$\begin{array}{l}\sigma_{\max } \\
\text { (MPa) }\end{array}$} & \multirow{2}{*}{$\begin{array}{l}\text { FOS- } \\
\text { YS }\end{array}$} & \multirow{2}{*}{$\begin{array}{c}\text { FOS } \\
\text {-US }\end{array}$} & \multicolumn{3}{|c|}{$66 \mathrm{Mev}$} & \multicolumn{3}{|c|}{$118 \mathrm{Mev}$} & \multicolumn{3}{|c|}{$200 \mathrm{Mev}$} \\
\hline & & & & $\begin{array}{l}\sigma_{\max } \\
(\mathrm{MPa})\end{array}$ & $\begin{array}{l}\text { FOS- } \\
\text { YS }\end{array}$ & $\begin{array}{c}\text { FOS- } \\
\text { US }\end{array}$ & $\begin{array}{l}\sigma_{\max } \\
(\mathrm{MPa})\end{array}$ & $\begin{array}{c}\text { FOS- } \\
\text { YS }\end{array}$ & FOS-US & $\begin{array}{l}\sigma_{\max } \\
(\mathrm{MPa})\end{array}$ & $\begin{array}{l}\text { FOS- } \\
\text { YS }\end{array}$ & $\begin{array}{l}\text { FOS- } \\
\text { US }\end{array}$ \\
\hline $48 "$ & 278 & 0.86 & 1.3 & 301 & 0.79 & 1.23 & 298.2 & 0.8 & 1.24 & 310 & 0.77 & 1.2 \\
\hline $24 "$ & 168.9 & 1.42 & 2.2 & 291.4 & 0.82 & 1.27 & 289.7 & 0.83 & 1.27 & & & \\
\hline $6 "$ & 47.3 & 5 & 7.8 & 249.7 & 0.96 & 1.48 & & & & & & \\
\hline
\end{tabular}

\section{Discussion}

Conduction, convection and radiation modes of heat transfer are considered for determining the temperature distribution in the window. In the steady state, the effect of Aluminum tube on the temperature of the window is insignificant. The maximum stress in the old Be window (0.012" thick and 48" radius of curvature) is beyond the yield stress, but less than the ultimate stress. Increasing the thickness won't help as the thermal stress would increase significantly due to high heat load. Stress due to pressure load is proportional to the radius of curvature of the window, but the window thickness has opposite effect on the stress. Lesser is the thickness, lesser is the heat load and hence less thermal stress. So a right combination of radius of curvature and window thickness could keep the stress below the yield stress. For the new window design 6" radius of curvature was selected and thickness remains unchanged. Higher bulge (lesser radius of curvature) facilitates the window expansion when get heated, thereby reduces the thermal stress. However, considering manufacturing difficulty, no less than 6" radius is considered here. 


\section{New Window}

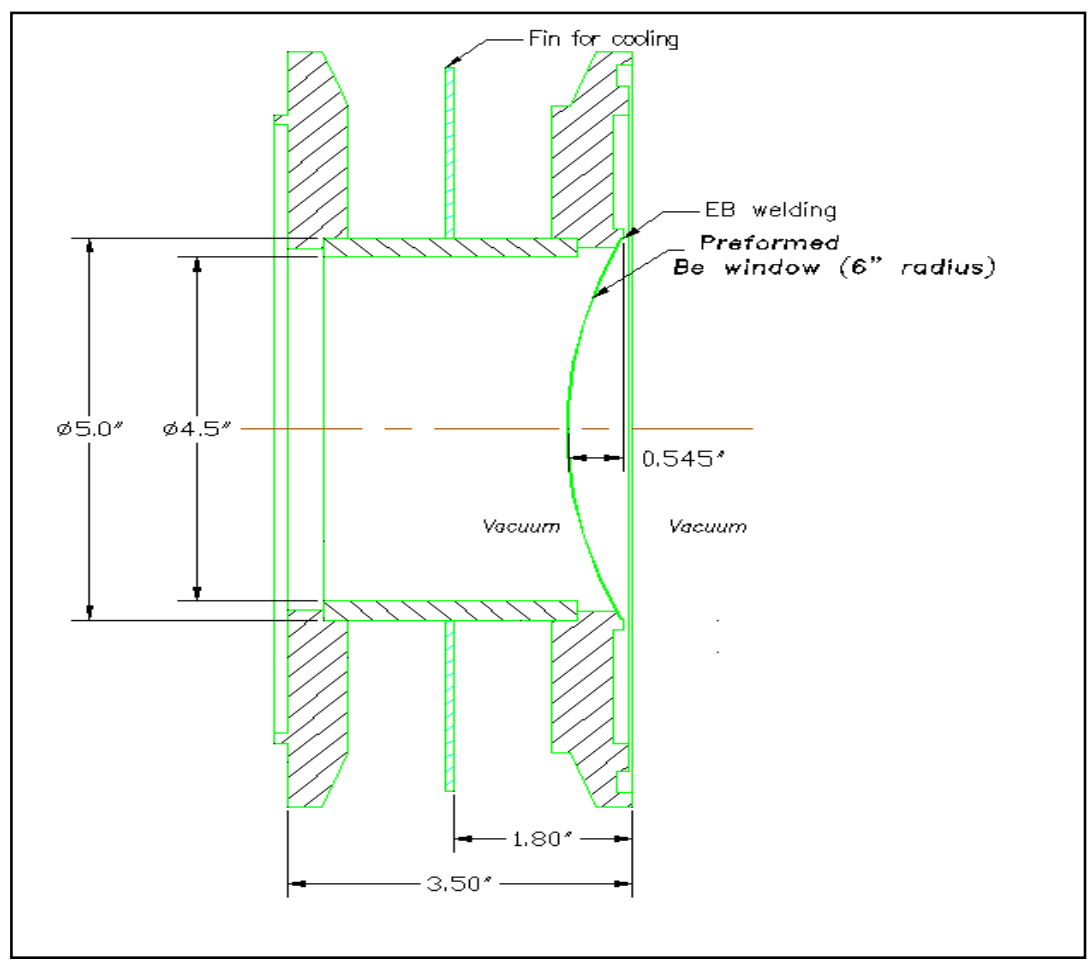

Fig 3-1: New window design, preformed $B e$ window (0.012" thick) welded to the $A l$ beam tube In the new design, both side of the window will have vacuum, hence eliminating the pressure load during operation. There is no direct convection mode of cooling from the window, however radiation heat transfer is considered. A circular fin is also added for better cooling of the window. Convective heat transfer coefficients are applied on flange, fin and tube faces which are exposed to air. Since the flange will be covered by clamps, the top areas aren't considered for convection heat transfer. From the detailed simulation of old window (Table 2-2), 6" radius of curvature was incorporated in new window design. The whole window assembly is considered for thermal simulation. The stress analysis is done in the same way as described section 2. 


\section{Thermal analysis of the window}

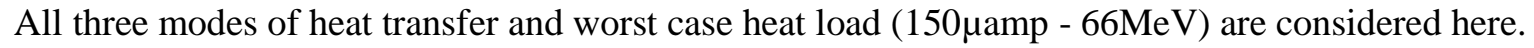

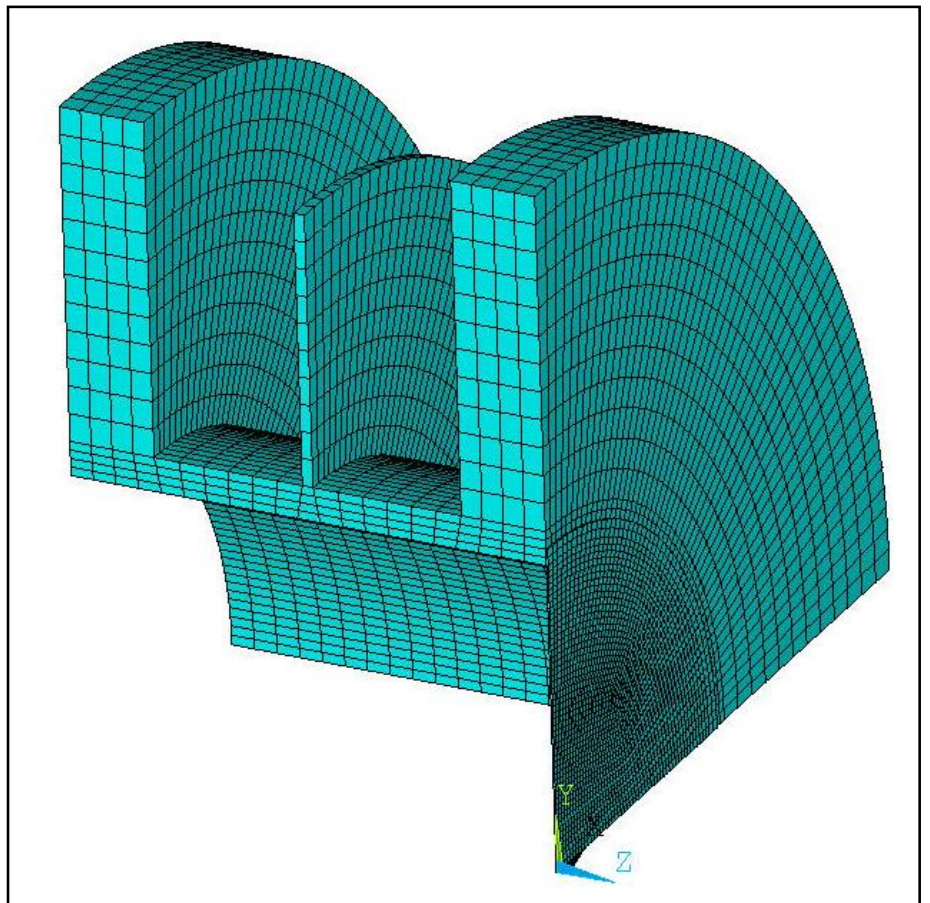

Fig 3-2: $1 / 4^{\text {th }}$ symmetric finite element model for thermal analysis

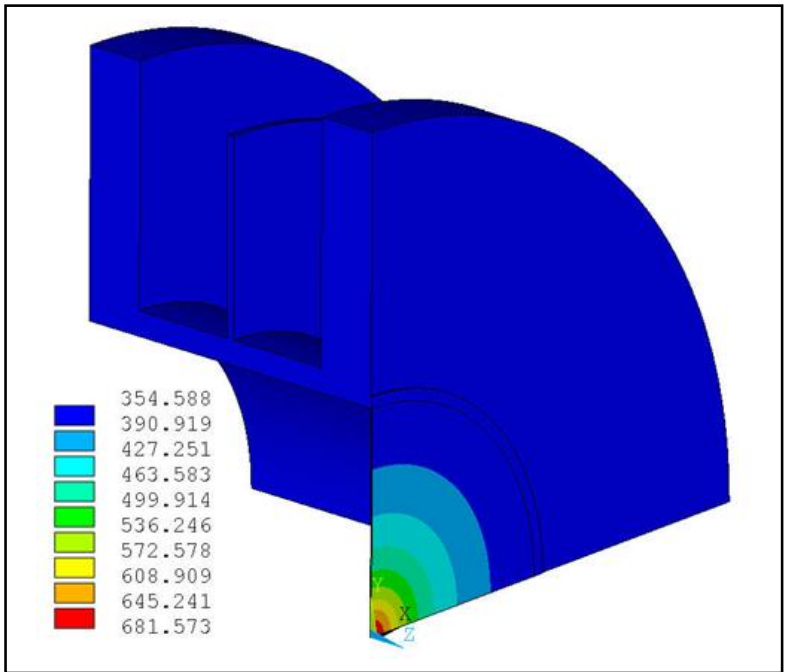

(a)

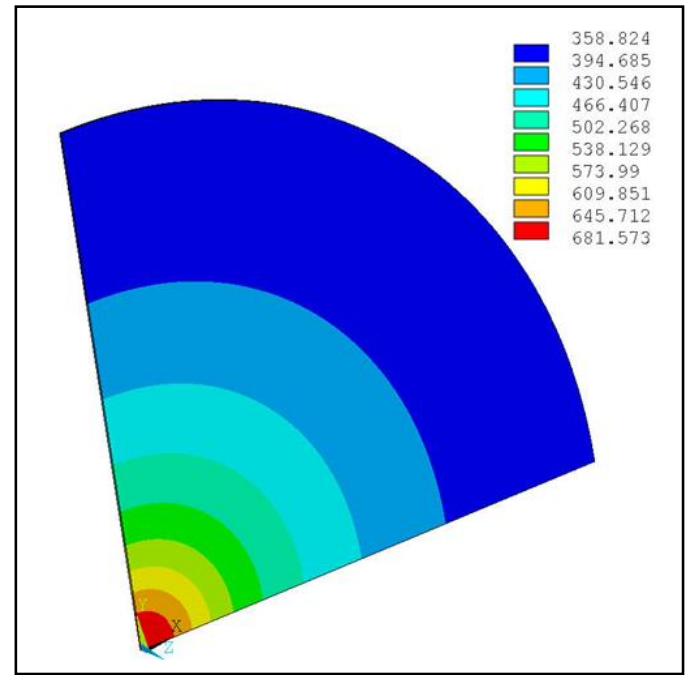

(b)

Fig 3-3: Contour plot of temperature (k) (a) full $1 / 4^{\text {th }}$ symmetric model and (b) only window 


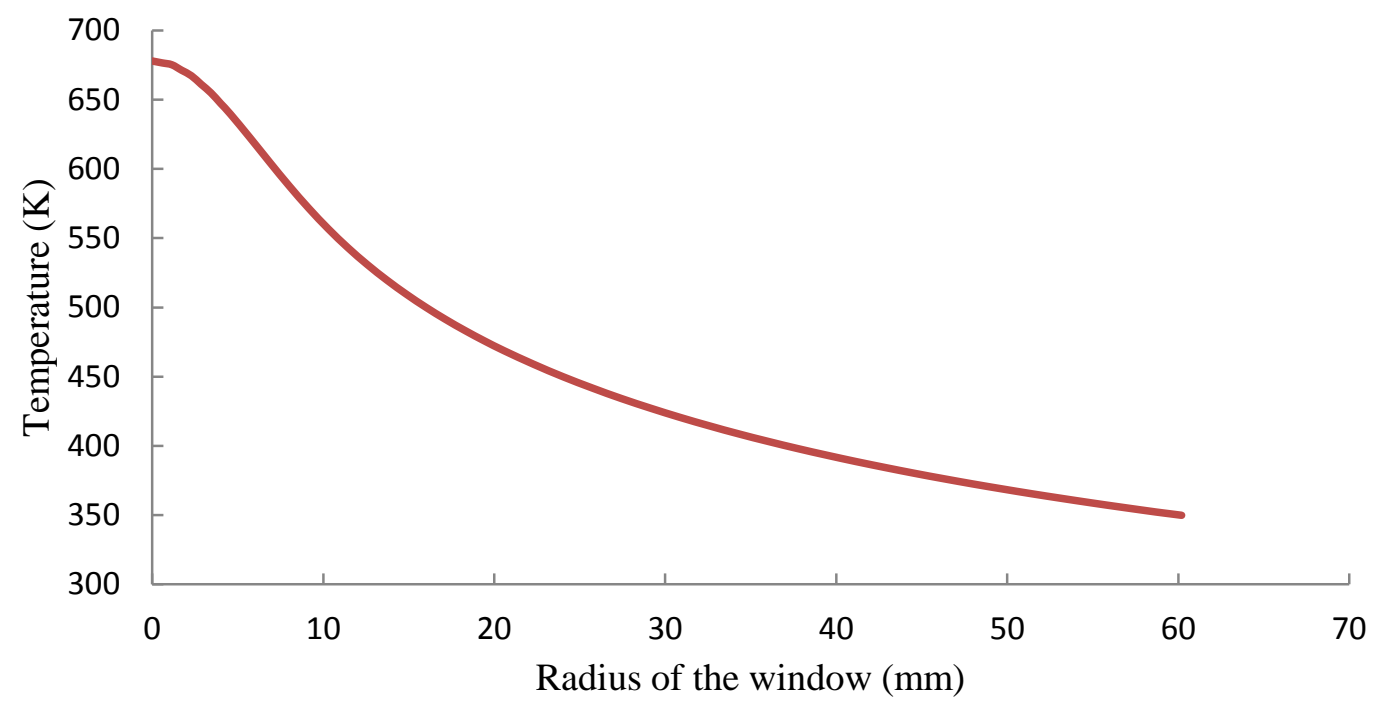

Fig 3-4: Temperature distribution in the window (66Mev)

Trend line is fitted in the above plot and an analytical expression is generated in terms of radius is generated. This expression is used to apply thermal load in structural analysis.

$\mathrm{T}=-2.02 \mathrm{e}-7 * \mathrm{r}^{6}+3.93 \mathrm{e}-5 * \mathrm{r}^{5}-2.9 \mathrm{e}-3 * \mathrm{r}^{4}+9.86 \mathrm{e}-2 * \mathrm{r}^{\wedge} 3-1.33 * \mathrm{r}^{2}-5.83 * \mathrm{r}+683.28, \mathrm{r}$ is the radial location in window

\section{Stress analysis of window}

Case-1: No pressure load, only thermal load

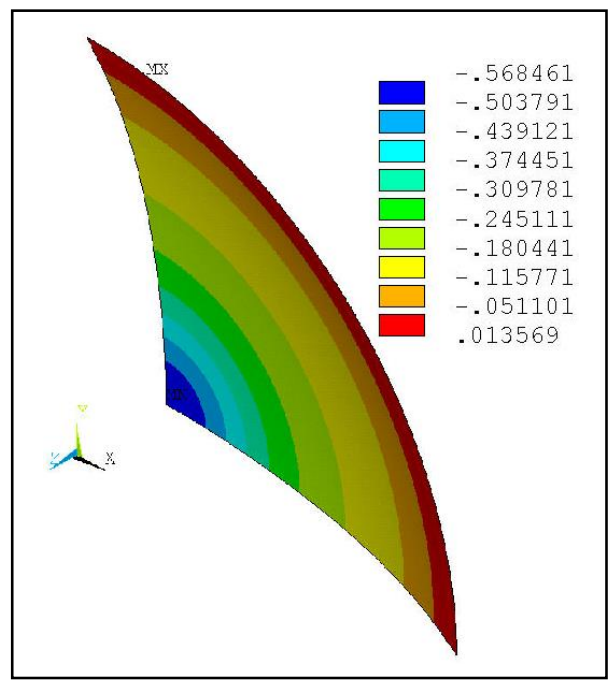

(a)

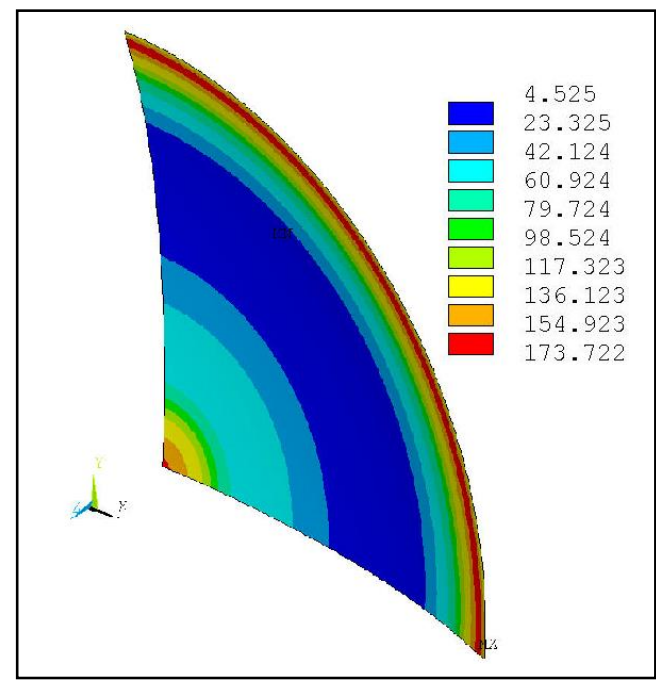

(b)

Fig 3-5: a) Axial deflection ( $\mathrm{mm}$ ) and (b) Von Misses stress (MPa) 
The maximum Von Misses stress (173.7 MPa) is well below the yield stress (240 MPa), so it is safer to operate the window with both side vacuum.

Case-2: Only pressure load from concave side (Note: Both pressure and thermal load can't occur simultaneously)

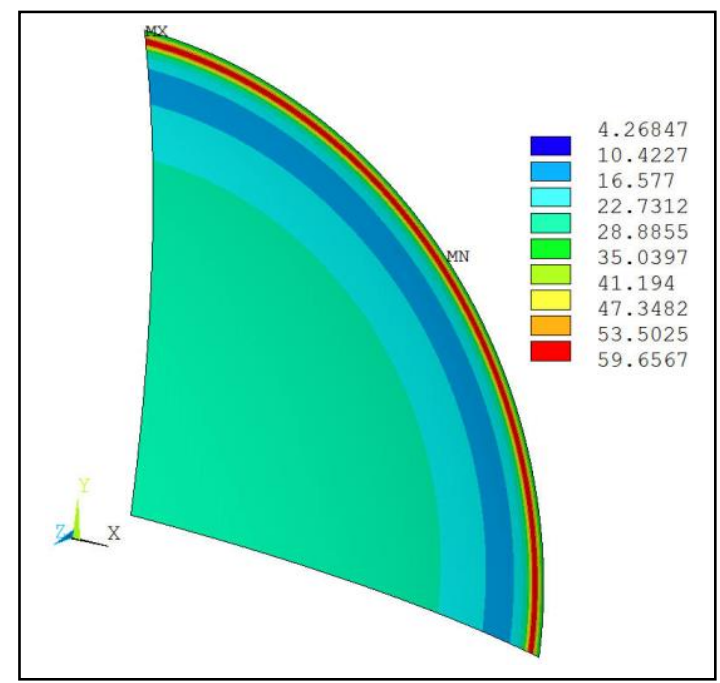

Fig 3-6: Von Mises stress (MPa) for only pressure load from concave side

Case-3: Only pressure load from convex side

Stress and deflection would be same as to case-2. A buckling simulation was carried out, the minimum buckling pressure load is 13.5 times atmospheric pressure.

\section{Turn buckle design}

The aluminum bellow installed in adjacent to the new Be window assembly has turn buckles (Fig 37). This facilitates for easy access to the window for replacement or inspection and thereby reduces the radiation dose received by personnel.

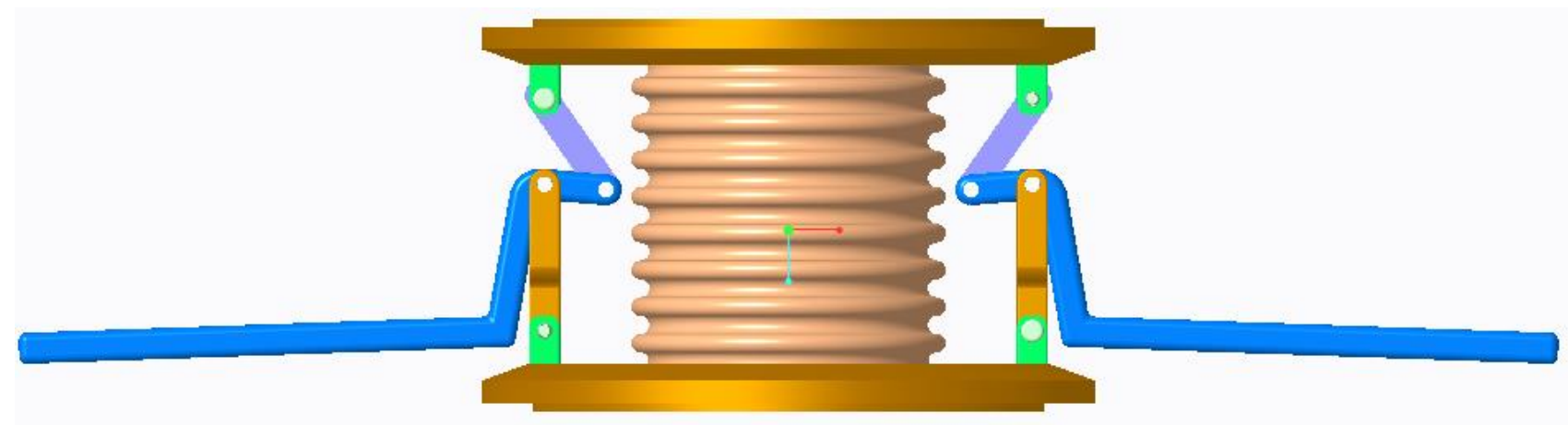

Fig 3-7: Aluminum bellow with turn buckles 


\section{Conclusion}

The new window design is proved to be safer than the existing window. It has been running since 2012 without a single failure. During operation, the window is only subjected to thermal load and the corresponding thermal stress is well below the yield stress. The absence of pressure load (primary load) reduces the chance of catastrophic failure. While one side of beamline is vented, the window only sees the pressure load, no thermal load. Window never sees the both pressure and thermal load simultaneously which is good for window life. Also, the new window eliminates the air activation (no air gap) and the exposure of the window to humid air (reduces the corrosion). The convex side of the window should be pumped down first to make sure that window sees the pressure from concave side. Though the stress in the window is similar to fig 5-6 under pressure load from convex side and the corresponding buckling pressure load is 13.5 times the atmospheric load, but we should maintain a practice to pump down first from convex side of the window. This practice will also reduce the fatigue load on the window.

\section{References:}

1. Raithby and Hollands, Handbook of heat transfer, $3^{\text {rd }}$ edition.

2. Mayville and Finnie, Uniaxial stress-strain curves from a bending test, Experimental Mechanics, 197-201. 


\section{Appendix}

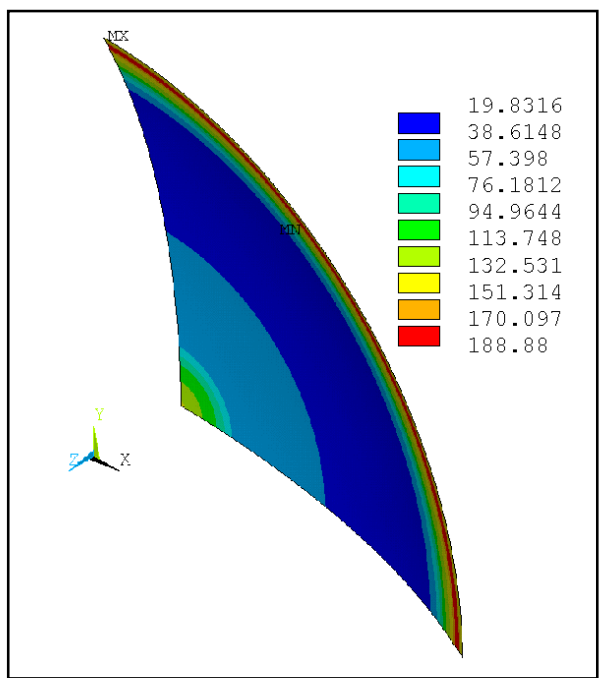

Fig A: Von Mises stress (MPa) for both thermal and pressure load for new window

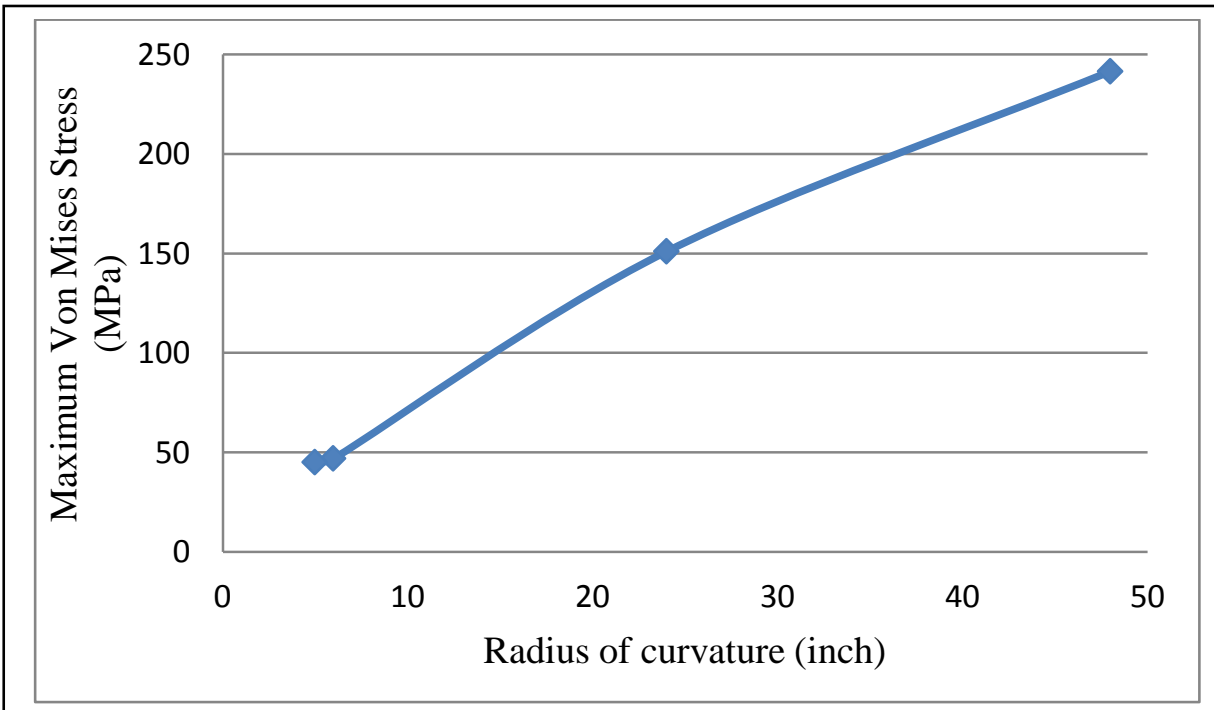

Fig B: Stress vs radius of curvature of old window for pressure load only 


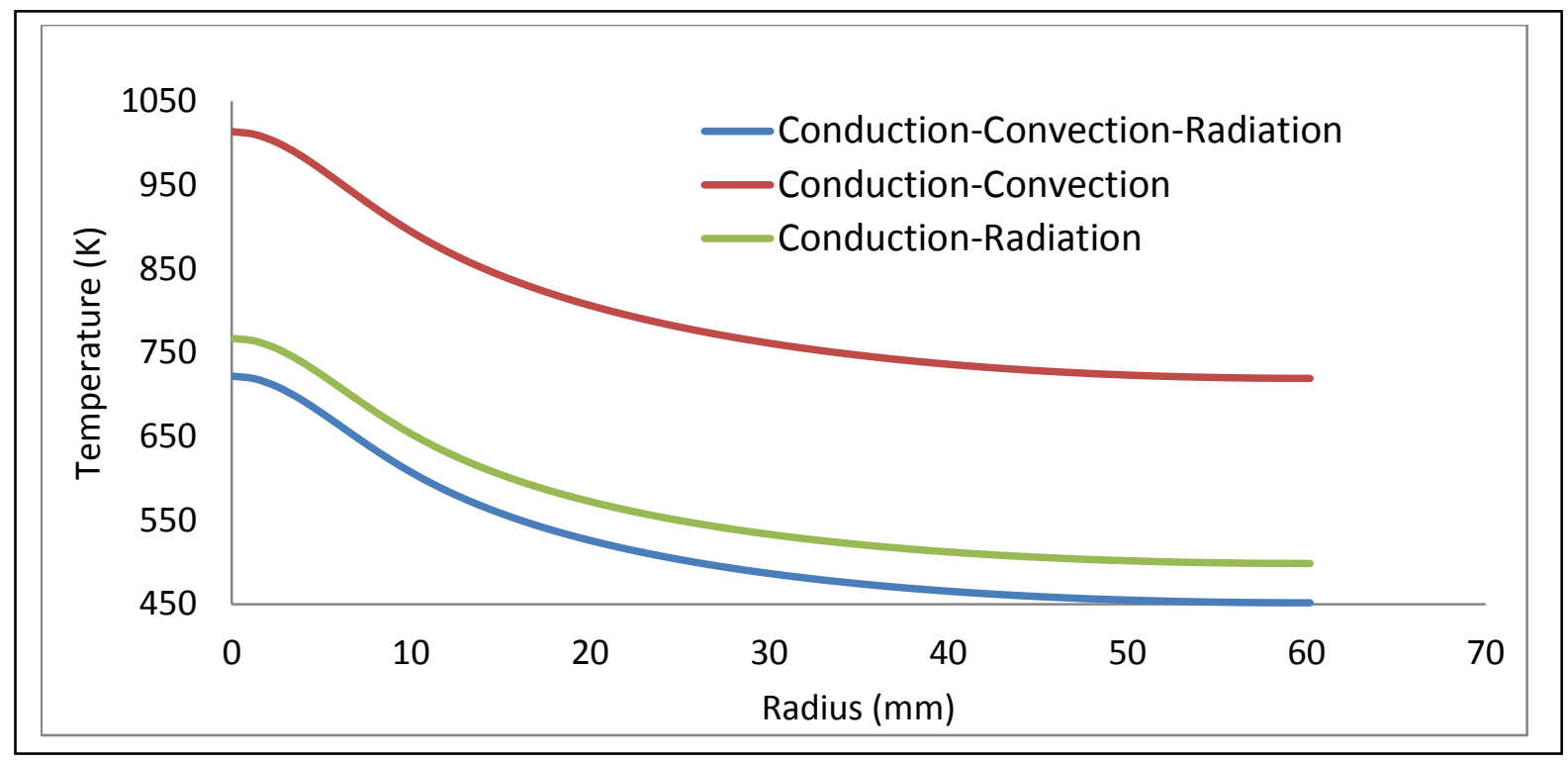

Fig C: Temperature distribution at different heat transfer mode for $66 \mathrm{Mev}$ beam energy and $150 \mu \mathrm{amp}$ beam current

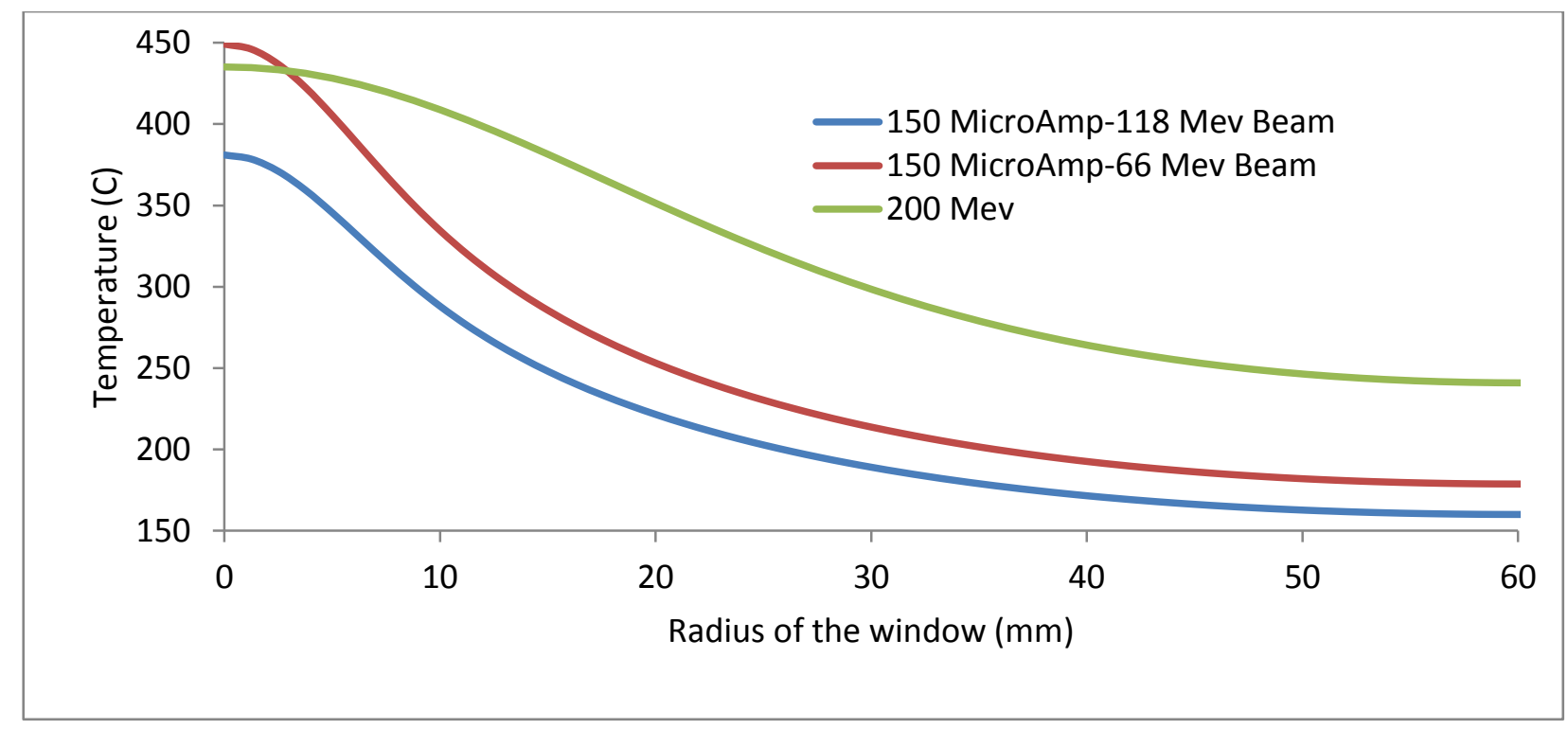

Fig D: Temperature distribution at different beam energy 


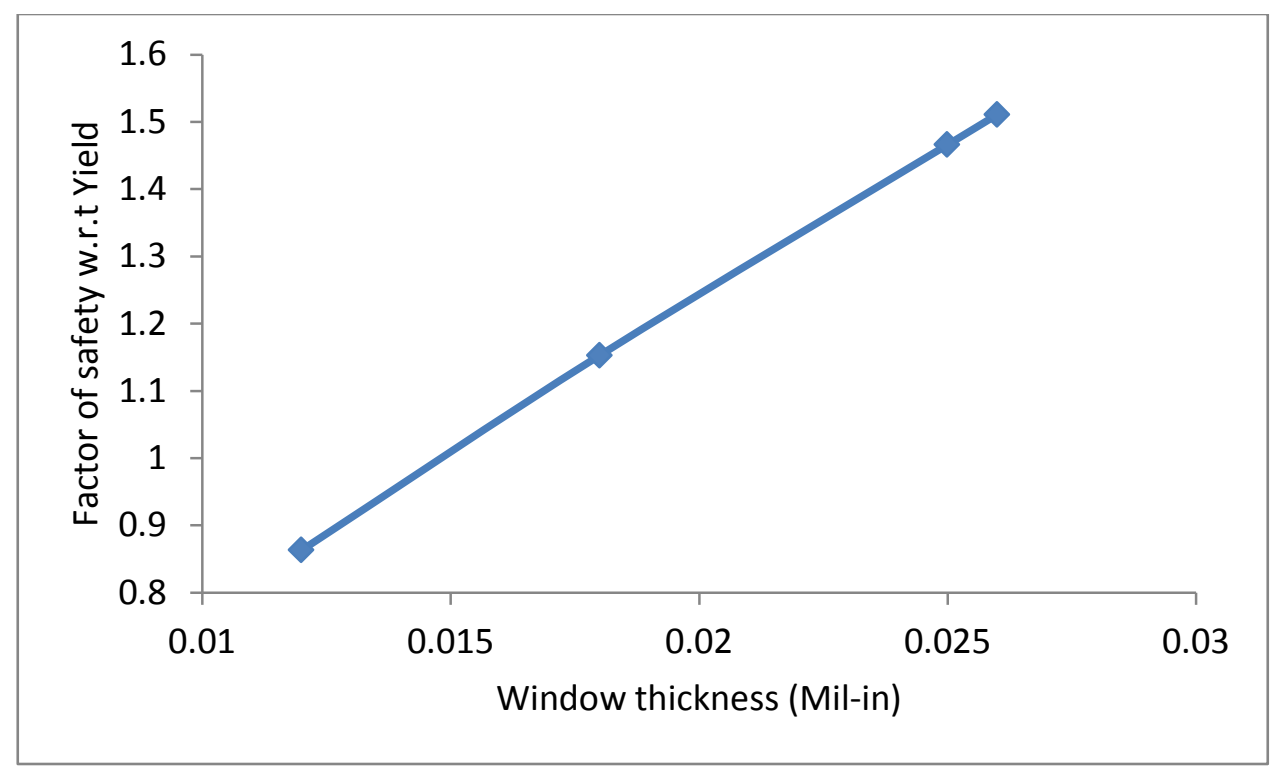

Fig E: Factor of safety for 48 " radius of curvature Be window

Table A: Maximum stress and factor of safety for 0.012 " thick Be (PF-60) window in FPS unit

\begin{tabular}{|c|c|c|c|c|c|c|c|c|c|c|c|c|}
\hline & \multicolumn{3}{|c|}{ Vacuum Load } & \multicolumn{9}{|c|}{ Vacuum + Thermal Load } \\
\hline \multirow{2}{*}{$\begin{array}{l}\text { Radius of } \\
\text { curvature }\end{array}$} & \multirow{2}{*}{$\begin{array}{l}\sigma_{\max } \\
(\mathrm{MPa})\end{array}$} & \multirow{2}{*}{$\begin{array}{c}\text { FOS- } \\
\text { YS }\end{array}$} & \multirow{2}{*}{$\begin{array}{l}\text { FOS } \\
\text {-US }\end{array}$} & \multicolumn{3}{|c|}{$66 \mathrm{Mev}$} & \multicolumn{3}{|c|}{$118 \mathrm{Mev}$} & \multicolumn{3}{|c|}{$200 \mathrm{Mev}$} \\
\hline & & & & $\begin{array}{c}\sigma_{\max } \\
(\mathrm{KPsi})\end{array}$ & $\begin{array}{c}\text { FOS- } \\
\text { YS }\end{array}$ & $\begin{array}{l}\text { FOS- } \\
\text { US }\end{array}$ & $\begin{array}{c}\sigma_{\max } \\
(\mathrm{KPsi})\end{array}$ & $\begin{array}{c}\text { FOS- } \\
\text { YS }\end{array}$ & FOS-US & $\begin{array}{l}\sigma_{\max } \\
(\mathrm{KPsi})\end{array}$ & $\begin{array}{c}\text { FOS- } \\
\text { YS }\end{array}$ & $\begin{array}{c}\text { FOS- } \\
\text { US }\end{array}$ \\
\hline $48^{\prime \prime}$ & 278 & 0.86 & 1.3 & 301 & 0.79 & 1.23 & 298.2 & 0.8 & 1.24 & 310 & 0.77 & 1.2 \\
\hline $24 "$ & 169 & 1.42 & 2.2 & 291.4 & 0.82 & 1.27 & 289.6 & 0.83 & 1.27 & & & \\
\hline $6 "$ & 47.3 & 5 & 7.8 & 249.6 & 0.96 & 1.48 & & & & & & \\
\hline
\end{tabular}

$$
\sigma_{\text {yield }}=240 \mathrm{Mpa} \quad \sigma_{\text {ultimate }}=370 \mathrm{Mpa}
$$

